\title{
Homocoupling of Phenylboronic Acid using Atomically Dispersed Gold on Carbon Catalysts: Catalyst Evolution Before Reaction
}

Tanja E. Parmentier ${ }^{\mathrm{a}}$, Simon R. Dawson ${ }^{\mathrm{a}}$, Grazia Malta ${ }^{\mathrm{a}}$, Li Lu ${ }^{\mathrm{b}}$, Thomas E. Davies ${ }^{\mathrm{a}}$, Simon A. Kondrat ${ }^{\mathrm{a}, \mathrm{c}}$, Simon J. Freakley ${ }^{\mathrm{a}}$, Christopher J. Kiely ${ }^{\mathrm{a}, \mathrm{b}}$ and Graham J. Hutchings ${ }^{\mathrm{a} *}$

${ }^{\text {a }}$ Cardiff Catalysis Institute, School of Chemistry, Cardiff University, Main Building, Park Place, Cardiff, CF10 3AT, UK.

${ }^{\mathrm{b}}$ Department of Materials Science and Engineering, Lehigh University, 5 East Packer Avenue, Bethlehem, Pennsylvania, 18015, USA

${ }^{c}$ Department of Chemistry, Loughborough University, Loughborough, Leicestershire, LE11 $3 T U, U K$

* hutch@cardiff.ac.uk 


\begin{abstract}
Coupling reactions to form new $\mathrm{C}-\mathrm{C}$ bonds are extensively used in industrial synthetic processes. Gold has been shown to be an active catalyst for such reactions however, conflicting reports exist as to whether cationic $\mathrm{Au}$ or metallic $\mathrm{Au}$ is acting as the active species. We prepared a heterogeneous catalyst consisting of atomically dispersed $\mathrm{Au}-\mathrm{Cl}_{\mathrm{x}}$ supported on carbon and showed this to be active in the homocoupling of phenylboronic acid to biphenyl. However; characterisation of the catalyst materials, even after just a short exposure time to the reactants, revealed rapid reduction and sintering of the $\mathrm{Au}$ species into larger metallic nanoparticles which we propose to be the true active species in this instance. This study suggests that if cationic $\mathrm{Au}$ is an active catalyst, it must be stabilised against reduction and agglomeration by either forming complexes which are more stable than common chlorides or by strongly anchoring them firmly onto alternative support materials; as in this case the carbon supported $\mathrm{Au}-\mathrm{Cl}$ species were easily reduced.
\end{abstract}


Coupling reactions to form new $\mathrm{C}-\mathrm{C}$ bonds are widely used in the pharmaceutical, agrochemical and fine chemical industries. ${ }^{[1]}$ Suzuki coupling catalysts are typically homogenous palladium-based catalysts that are used to couple organo-boron compounds with organic halides or triflates, forming new C-C bonds. ${ }^{[2]}$ One of the most widely used coupling reactions in an industrial context is the synthesis of the fungicide Boscalid, where Pd-based catalysts are used in a Suzuki coupling reaction to produce a biaryl intermediate in a one-step reaction process, rather than the five synthetic steps previously utilised. ${ }^{[1 \mathrm{a}]}$ The substrate tolerance and general applicability of these transformations make such coupling catalysts a key synthetic tool in the production of many high value materials.

Typically the catalytic cycle of the palladium catalysed reaction under basic conditions involves the oxidative addition of the aryl halide to a $\mathrm{Pd}(0)$ centre followed by a transmetalation of an aryl substituent from a boronate species to generate a di(aryl) $\operatorname{Pd}(\mathrm{II})$ species. Reductive elimination of the di(aryl) species then regenerates the initial $\operatorname{Pd}(0)$ centre. ${ }^{[3]}$ Extensive studies have been conducted on the development of homogeneous Pd catalysts for numerous organic transformations, however, the final separation of such catalysts from the reaction mixtures remains a significant challenge. Heterogeneous-type Suzuki coupling catalysts have also been synthesised by immobilising palladium complexes onto high surface area supports (e.g., silica, zeolites and activated carbon) thus allowing the catalysts to be more easily separated from the product by filtration. ${ }^{[4]}$

Besides palladium-based materials, several other metals have been proposed to be effective catalysts for these reactions. Corma et al. postulated and subsequently demonstrated that $\mathrm{Au}$ (III) could be active as a Suzuki coupling catalyst due to (i) Au(III) being isoelectronic with $\mathrm{Pd}(\mathrm{II})$ and (ii) the redox couple of $\mathrm{Au}(\mathrm{III})-\mathrm{Au}(\mathrm{I})$ being isoelectronic with the $\mathrm{Pd}(\mathrm{II})-\mathrm{Pd}(0)$ species needed to effect the reaction. ${ }^{[5]}$ Carbon - carbon coupling has also been observed by $\mathrm{Au}(\mathrm{I})$ complexes via transmetallation of $\mathrm{Au}(\mathrm{I})$ to $\mathrm{Pd}(\mathrm{II}) .{ }^{[6]}$ Corma and co-workers prepared gold supported on nanocrystalline ceria and demonstrated that this material was able to catalyse the homocoupling of phenylboronic acid in the presence of a base. In subsequent FT-IR studies they were able to demonstrate that the activity of the $\mathrm{Au} / \mathrm{CeO}_{2}$ catalyst is directly proportional to either (i) the concentration of $\mathrm{Au}$ (III) species present on the gold nanoparticles / support interface or (ii) the concentration of highly dispersed cationic Au species stabilised on the $\mathrm{CeO}_{2}$ support material. ${ }^{[7]}$ To demonstrate the catalytic activity of cationic-species, a Au(III) Schiff base complex was synthesised and shown to be active in this reaction. ${ }^{[8]} \mathrm{Au}$ (III) has also been able to form carbon - carbon bonds by oxidative coupling of vinyl groups in vinylgold intermediates. ${ }^{[9]}$ In addition, simple gold-containing salts like $\mathrm{AuCl}$ and $\mathrm{NaAuCl}_{4}$ have also reported to be active in the homocoupling of phenylboronic acids. ${ }^{[10]}$ Recently a photochemical, visible light induced Suzuki-type coupling of arylboronic acid and aryldiazonium satls was developed. ${ }^{[1]}$ Guzman et al. also showed that metallic gold nanoparticles supported on both $\mathrm{CeO}_{2}$ and $\mathrm{ZrO}_{2}$ are also active in the homocoupling reaction of phenylboronic acid. ${ }^{[12]}$ The activity of these catalysts has also been correlated to the crystallite size of the support material, with smaller crystallites being better able to stabilise the $\mathrm{Au}$ (III) species. Hasmi and co-workers also observed homocoupling of boronic acids when they prepared gold (III) complexes from boronic acids. ${ }^{[13]}$

These studies collectively suggest the $\mathrm{Au}(\mathrm{III})$ species are the active entities for this reaction. However, more recently multiple studies have claimed otherwise and demonstrated the activity 
of gold nanoparticles in the reaction. For instance, PVP-stabilised Au colloids in aqueous solution have been shown to be active, as have base-free metallic Au na noparticles supported on $\mathrm{Al}-\mathrm{Mg}$ oxides. ${ }^{[6 \mathrm{~b}, 14]}$

Malta et. al. recently demonstrated using in-situ X-ray absorption spectroscopy (XAS) studies that the active form of the $\mathrm{Au} / \mathrm{C}$ catalyst used for acetylene hydrochlorination is comprised of atomically dispersed $\mathrm{AuCl}_{\mathrm{x}}$ species which are thermally stable under high temperature conditions (i.e., $200{ }^{\circ} \mathrm{C}$ ). ${ }^{[15]}$ The acetylene hydrochlorination reaction is proposed to occur via the $\mathrm{Au}(\mathrm{I})$ - $\mathrm{Au}(\mathrm{III})$ redox cycle as predicted through correlations with standard electrode potentials, which suggested to us that this catalyst could also be active as a homocoupling catalyst. ${ }^{[16]}$ In this study, we have investigated this $\mathrm{Au} / \mathrm{C}$ single site catalyst for the homocoupling of phenylboronic acid and compared it's performance to that of a solimmobilised $\mathrm{Au} / \mathrm{C}$ nanoparticle catalyst and a simple gold salt $\left(\mathrm{HAuCl}_{4}\right)$.

\section{Results \& Discussion}

The recent discovery that gold cations dispersed on high surface area activated carbon supports can catalyse the gas phase acetylene hydrochlorination reaction at high temperatures suggested that not only can single atom catalysts operate and retain an atomic dispersion under harsh reaction conditions, but that they could become technologically significant in some industrial processes. ${ }^{[15 a]}$ Homocoupling to create new C-C bonds is widely used in the synthesis of many chemical materials, and cationic Au species have been postulated to be for active for such reactions, either at the interfacial periphery of supported metallic nanoparticles or stabilised as isolated species on oxide materials. We have prepared $1 \mathrm{wt} \% \mathrm{Au} / \mathrm{C}$ catalysts by the immobilisation of colloidal metal Au nanoparticles and through the impregnation of $\mathrm{Au}$ from aqua regia (to generate atomically dispersed $\mathrm{AuCl}_{\mathrm{x}}$ species) using a high surface area activated carbon material as catalyst support.

X-ray diffraction (XRD) patterns of the catalysts prepared by sol immobilisation, (1\% Au/C $(\mathrm{sol}))$ and with aqua regia (1\% Au/C (AR)), are shown in Figure 1(a). In the case of the 1\% $\mathrm{Au} / \mathrm{C}$ (sol) catalyst, where polymer stabilised metallic nanoparticles existed in solution prior to immobilisation, a clear diffraction pattern consistent with f.c.c. Au (ICCD 01-071-4164) was obtained, with the principal reflection at $38^{\circ}(2 \Theta)$, corresponding to the set of $\mathrm{Au}\{111\}$ planes. Analysis using the Scherrer equation suggested an average crystallite size of $6 \mathrm{~nm}$ in this (1\% $\mathrm{Au} / \mathrm{C}(\mathrm{sol})$ ) sample. In contrast, the fresh $1 \% \mathrm{Au} / \mathrm{C}(\mathrm{AR})$ sample showed no features consistent with the presence of Au nanocrystals implying a high dispersion of Au existed in this catalyst. Figure 1(b) however demonstrated that heat treatment of the $1 \% \mathrm{Au} / \mathrm{C}(\mathrm{AR})$ catalyst, under a nitrogen atmosphere (in order to prevent combustion of the carbon support material), during an in-situ XRD experiment eventually caused sintering of the $\mathrm{Au}$ species into discrete detectable metallic nanoparticles. Figure 1(b) demonstrates that no diffraction peaks characteristic of f.c.c Au were observed until the temperature of the reaction cell reached 310 ${ }^{\circ} \mathrm{C}$. This implies that the Au species in the $1 \% \mathrm{Au} / \mathrm{C}(\mathrm{AR})$ sample have a tendency to remain in a highly dispersed state even at elevated temperatures up to $300{ }^{\circ} \mathrm{C}$. When the temperature 
was increased above $310{ }^{\circ} \mathrm{C}$, the evolution of more distinct diffraction patterns showed the growth of these Au crystallites through thermally activated mobility of the Au species.

Transmission electron microscopy (TEM) analysis of the $1 \% \mathrm{Au} / \mathrm{C}$ (sol), Figure 2(a), revealed homogeneous dispersion of Au nanoparticles on the activated carbon support. Analysis of the particle size distribution from such micrographs (Figure 2(b)) gave a mean particle size of 6.6 $\mathrm{nm}$ with a spread of about $\pm 3 \mathrm{~nm}$, which is consistent with the value derived from XRD measurements. This particle size distribution is comparable with the previously reported $\mathrm{Au}$ nanoparticle catalysts prepared for this reaction which were supported on $\mathrm{CeO}_{2}$ and $\mathrm{ZrO}_{2}{ }^{[12]}$ However, in direct contrast to these materials which were reported to contain substantial populations of $\mathrm{Au}^{\delta+}$ stabilised by the oxide support, X-ray photoemission spectroscopy (XPS, Figure 2(c)) of our $1 \% \mathrm{Au} / \mathrm{C}$ ( $\mathrm{sol}$ ) catalyst showed it to consist of exclusively metallic Au with a characteristic binding energy of $84 \mathrm{eV}$. This difference in Au speciation is probably due to the catalyst being prepared by a sol-immobilisation method in the presence of a strong reductant, $\mathrm{NaBH}_{4}$, which facilitates complete reduction of the $\mathrm{HAuCl}_{4}$ precursor. STEMHAADF analysis of the fresh $1 \% \mathrm{Au} / \mathrm{C}$ (AR) catalyst, (Figure 3), revealed the presence of a near complete atomic dispersion of $\mathrm{Au}$ species on the carbon support, once again consistent with our deductions from XRD analysis. XPS analysis of this $1 \% \mathrm{Au} / \mathrm{C}$ (AR) sample also suggested the presence of metallic Au. However, it is now well recognised that $\mathrm{Au}-\mathrm{Cl}_{\mathrm{X}}$ species supported on carbon can be susceptible to reduction by the X-ray flux used in XPS analysis resulting in the generation of $\mathrm{Au}$ clusters and nanoparticles from highly dispersed cationic species. ${ }^{[15 a, 16-17]}$

X-ray absorption spectroscopy (XAS) was carried out on the fresh $1 \% \mathrm{Au} / \mathrm{C}$ (AR) catalyst to verify that the fresh catalyst contained only highly dispersed cationic Au species rather than the metallic $\mathrm{Au}$ species detected by XPS analysis. The normalised $\mathrm{Au} \mathrm{L}_{3}$ - edge X-ray absorption near edge structure (XANES), shown in Figure 4(a), supported the HAADF-STEM analysis and confirmed that this catalyst consisted of highly dispersed cationic Au species. The presence of a white line absorption feature (indicative of partial 5d band occupancy) having a normalised intensity value of 0.76 when compared to appropriate standards (protocol reported in ${ }^{[15 a]}$ and used for the analysis presented in this study) suggested that the catalyst comprised of a mixture $\mathrm{Au}(\mathrm{I}) / \mathrm{Au}(\mathrm{III})$ species with no features of the post-edge spectrum being consistent with bulk Au. In addition, significant intensity in the Fourier transform (FT) corresponding to references for $\mathrm{Au}-\mathrm{Cl}$ type species can be seen in the extended X-ray absorption fine structure (EXAFS) presented in Figure 4(b). These findings are consistent with our previous reports on the preparation of active atomically dispersed $\mathrm{Au} / \mathrm{C}$ catalysts for the acetylene hydrochlorination reaction. ${ }^{[15 a]}$

Using these catalysts, we conducted homocoupling reactions using phenylboronic acid in the presence of base to produce biphenyl as the major coupling product. These reactions were performed in air, the oxygen present in the air is might be a stoichiometric oxidant during the reaction. It should be noted that phenol was produced as the minor product in all reactions as a result of oxidation of the aryl boronate species in solution. Figure 5(a) shows the conversion versus time-on-line profiles for the $1 \% \mathrm{Au} / \mathrm{C}(\mathrm{AR})$ and $1 \% \mathrm{Au} / \mathrm{C}$ (sol) heterogeneous reactions and the $\mathrm{HAuCl}_{4}$ homogeneous reaction. Each reaction was performed with an equal amount of 
gold $(0.005 \mathrm{mmol})$. The $1 \% \mathrm{Au} / \mathrm{C}$ (sol) catalyst showed minimal conversion $(2-3 \%)$ of phenylboronic acid throughout the $6 \mathrm{~h}$ reaction period. While many reports claim that oxide supported nanoparticles are active for this reaction, in this particular case the PVA stabilised $\mathrm{Au}$ particles dispersed on $\mathrm{C}$ were inactive despite having a mean particle size comparable to those in these other studies. ${ }^{[12,14 a, 14 b, 18]}$ As in many examples of catalysis using polymer stabilised nanoparticles, it is known that the presence of the ligand can hinder reactivity through blocking of the active sites. In addition, other studies utilised wet impregnation methods to produce nanoparticulate Au catalysts that were free of polymer stabilisers. In this case, with PVA being sparingly soluble in the reaction solvent, it is highly likely that the catalytic surface is completely blocked by the PVA polymer residing on the nanoparticles after preparation, especially as there is precedent in the literature for activity in the case of PVP-stabilised colloidal Au which demonstrates that Au nanoparticles in this size range can in some instance be active. ${ }^{[18]}$

The catalyst prepared using aqua regia $(1 \% \mathrm{Au} / \mathrm{C}(\mathrm{AR}))$, which is initially atomically dispersed, shows good activity for the homocoupling of phenylboronic acid reaction, reaching $25 \%$ conversion after $6 \mathrm{~h}$. The progressive increase of conversion value with increasing reaction time also suggests that there is no catalyst deactivation occurring. In common with the $1 \%$ $\mathrm{Au} / \mathrm{C}(\mathrm{AR})$ catalyst, the homogeneous reaction carried out using $\mathrm{HAuCl}_{4}$ also reached $24 \%$ conversion after $6 \mathrm{~h}$ of reaction. However, it should be noted that the conversion tends to plateau over the course of the reaction in this latter case. Figure 5(b) summarises the selectivity values obtained for each of the catalysts system. The $1 \% \mathrm{Au} / \mathrm{C}$ (sol) catalyst produced only traces of biphenyl at the low conversions achieved, and displayed a meagre $4 \%$ selectivity, confirming the proposed mechanism in the literature that phenol production is not a consecutive reaction of biphenyl. Reactions using biphenyl as the reactant resulted in no significant phenol production. The $1 \% \mathrm{Au} / \mathrm{C}(\mathrm{AR})$ catalyst produced biphenyl as the major product at $60.5 \%$ selectivity irrespective of conversion levels, along with a significant amount of phenol, typically $39.5 \%$. Due to the limited scope of this study, which was purely to investigate the effectiveness of this class of catalysts for homocoupling reactions as compared to solimmobilised catalysts, no additional experiments were conducted to optimise the potential yield of biphenyl over phenol.

It has been reported that simple Au-chloride salts are active catalysts for this reaction. In addition many studies show that metallic Au nanoparticles, even after additional treatment with $\mathrm{NaBH}_{4}$ to remove any cationic species, can still be active catalysts, especially when dispersed on basic support materials. ${ }^{[10,14 a]}$ Due to the similar activity levels displayed by the $\mathrm{HAuCl}_{4}$ and the $1 \% \mathrm{Au} / \mathrm{C}(\mathrm{AR})$ catalyst, that latter of which is known to consist of supported $\mathrm{Au}-\mathrm{Cl}$ species in the fresh catalyst, we further investigated the stability of our catalyst. ${ }^{[15 a]}$ Characterisation of the $1 \% \mathrm{Au} / \mathrm{C}(\mathrm{AR})$ catalyst after $6 \mathrm{~h}$ of reaction by XANES, as shown in Figure 6(a), revealed a significant evolution of the catalyst structure, which now much more closely resembled the metallic Au standard. Furthermore, EXAFS analysis shown in Figure 6(b) revealed significant $\mathrm{Au}-\mathrm{Au}$ interactions when comparing against the observed intensity of the Fourier transform with that of the metallic Au standard. The Au-Cl FT intensity was greatly reduced compared to the fresh catalyst (Figure 4(a)) suggesting that the atomic dispersion had become unstable and undergone significant sintering under reaction conditions. A linear 
combination fitting analysis (using $\mathrm{KAuCl}_{4}, \mathrm{AuCl}$ and metallic Au standards) of the fresh and used $1 \% \mathrm{Au} / \mathrm{C}(\mathrm{AR})$ samples shown in Figure 7(a) confirmed that the Au was cationic in nature in the fresh sample and had roughly a 1:1 $\mathrm{Au}$ (I) to $\mathrm{Au}$ (III) chloride species. TEM analysis, Figure 7(b), of the $1 \% \mathrm{Au} / \mathrm{C}(\mathrm{AR})$ sample after reaction showed that the catalyst now consisted of large nanoparticles with a mean particle size of between 30-40 nm (representative image shown in Figure 7(c)) supporting the XAS analysis. Despite this high degree of sintering, even after filtering of the reaction solution, only very low amounts of $\mathrm{Au}(9 \mathrm{ppb})$ were measured by ICP-MS in the reaction solution.

A sample of the $1 \% \mathrm{Au} / \mathrm{C}(\mathrm{AR})$ catalyst was recovered from the reaction after $6 \mathrm{~h}$, washed with $\mathrm{EtOH}$ and then dried before being retested. The activity of this sample was re-tested for durations of 1 and $2 \mathrm{~h}$ due to the sample showing no deactivation during the initial reaction time-on-line. Figure 8 shows that this catalyst showed similar activity upon re-use when compared to the fresh sample, which suggests that the catalyst nanostructure did not change significantly during the reaction itself and the transformation from an atomically dispersed to a nanocrystallline form occurred immediately on exposure to the reactants. It was also observed during the reaction using the homogeneous $\mathrm{HAuCl}_{4}$ catalyst, that the colour of the reaction solution changed from yellow to purple suggesting Au reduction from a cationic to metallic form under the reaction conditions. To confirm if the similar reduction was occurring in the supported $1 \% \mathrm{Au} / \mathrm{C}(\mathrm{AR})$ catalyst, this catalyst was suspended in a solution containing all the ingredients for reaction and was filtered after only $5 \mathrm{~min}$ of contact at room temperature. SEM analysis (Figure S1) revealed the presence of Au nanoparticles in the size range observed previously by TEM in the sample that had been used for $6 \mathrm{~h}$. This coupled with the observation that the catalyst displayed a constant reaction rate and is re-usable, supports the hypothesis that it is the initial exposure to the reactants that causes the significant rapid reduction and aggregation of the atomically dispersed Au species into particulate form.

We propose that previous reports which concerned the use of $\mathrm{HAuCl}_{4}$ and $\mathrm{AuCl}$ as catalysts for the homocoupling of phenylboronic acid, could in fact undergo a similar significant reduction to metallic nanoparticles either under reaction conditions or even just on mere exposure to the reactants. Stable Au cations in a system which uses polar solvents to allow complete dissolution of the base and reactants, will require strong interaction with the support material. The use of supports such as $\mathrm{CeO}_{2}, \mathrm{ZrO}_{2}$ or $\mathrm{TiO}_{2}$ which can stabilise Au cations at the nanoparticle interface periphery or at surface vacancies sites has been previously reported. So has the use of Au cationic complexes with high stability constants, such as the Schiff bases, ${ }^{[7}$, 12, 19]. Such stabilisation strategies are important as the stability of $\mathrm{Au}-\mathrm{Cl}$ species towards the reactants is minimal in the case of our $1 \% \mathrm{Au} / \mathrm{C}(\mathrm{AR})$ catalyst. The reduction of the $\mathrm{Au}-\mathrm{Cl}$ entities in our case presumably occurs by the oxidation of the aryl boronate species generated in-situ through reaction of the phenylboronic acid with the added base, which results in phenol production and the reduction of the Au species. The activity levels of the non-ligand protected gold nanoparticles produced in this study compare favourably with the activities reported for the $\mathrm{Au} / \mathrm{CeO}_{2}$ and $\mathrm{Au} / \mathrm{ZrO}_{2}$ systems taking into account the differences in particle size and reaction conditions. To better understand the role of cationic Au in these coupling reactions, more stable cationic Au complexes are required which display a better stability to the reducing nature of the boronate species. However, this enhanced stability may come at a cost in terms of the overall reactivity. Our future studies on this reaction will focus on the use of sulfur- 
stabilised $\mathrm{Au} / \mathrm{C}$ catalysts which have been shown to be especially stable in the acetylene hydrochlorination reaction. ${ }^{[20]}$

\section{Conclusions}

We prepared an atomically dispersed $\mathrm{Au} / \mathrm{C}$ catalyst using an aqua regia impregnation method as a model for supported cationic Au complexes which have been previously used as catalysts for the homocoupling of phenylboronic acid. This catalyst showed activity in the homocoupling of phenylboronic acid towards biphenyl and was re-usable. However, detailed structural characterisation revealed that exposure to the reactants resulted in rapid reduction and agglomeration of the Au species into nanoparticles. The activity of the reduced Au species was comparable to that described in previous reports, and our experiments demonstrated that supported cationic $\mathrm{Au}-\mathrm{Cl}_{\mathrm{x}}$ is not stable to the reducing species present in the reaction solution. To fully elucidate the role of cationic Au more stable complexes need to be produced and investigated. However, this may reduce the overall activity of the catalysts by restricting the action of the redox cycle required for the reaction to proceed. 


\section{Experimental}

The $1 \mathrm{wt} \% \mathrm{Au} / \mathrm{C}(\mathrm{AR})$ catalyst was prepared by a wet impregnation with aqua regia. Powdered activated carbon (Norit ROX 0.8, 100 - 140 mesh) was used as support. $\mathrm{HAuCl}_{4} \cdot \mathrm{XH}_{2} \mathrm{O}$ (Alfa Aaesar, $99.9 \%$ ) was dissolved in $5.4 \mathrm{~mL}$ aqua regia (3 parts by volume [ $\mathrm{HCl}$ (Fisher, 32 wt.\%)]: 1 part by volume $\left[\mathrm{HNO}_{3}\right.$ (Fisher, $70 \mathrm{wt}$. \%)]) and added dropwise to the activated carbon while being stirred continuously. The mixture was left to stir for $60 \mathrm{~min}$ at room temperature after which it was placed in a furnace at $140{ }^{\circ} \mathrm{C}$ for $16 \mathrm{~h}$ under a $\mathrm{N}_{2}$ flow. Sol immobilisation was used to prepare another $\mathrm{Au} / \mathrm{C}$ catalyst (designated $\mathrm{Au} / \mathrm{C}(\mathrm{sol})$ ). For this preparation aqueous solutions of $\mathrm{HAuCl}_{4} .3 \mathrm{H}_{2} \mathrm{O}$ ((Alfa Aesar, $\left.99.9 \%\right)$ and polyvinyl alcohol (PVA) (1wt\%, Aldrich, MW 9000-10000, 80\% hydrolysed) were prepared. The desired amount of these solutions (to make $1 \mathrm{wt} \% \mathrm{Au}$ and $\mathrm{Au} / \mathrm{PVA}$ w/w=1.2) was added to $800 \mathrm{~mL}$ of water. A fresh solution of $\mathrm{NaBH}_{4}(0.1 \mathrm{M}$, Aldrich, 99.99\%) was prepared and $6.6 \mathrm{ml}$ added to the Au+PVA solution $\left(\mathrm{NaBH}_{4}: \mathrm{Au}=5: 1\right)$. It was then stirred for 30 mins to allow the sol to generate. The carbon support (Norit ROX 0.8, 100 - 140 mesh, desired amount for $1 \mathrm{wt} \% \mathrm{Au}$ loaded catalyst) was then added to the sol mixture, together with a few drops of concentrated $\mathrm{H}_{2} \mathrm{SO}_{4}$ (Fisher Laboratory reagent grade, $>95 \%$ ). After $1 \mathrm{~h}$ of stirring the mixture was filtered, washed thoroughly with distilled water, and left to dry for $16 \mathrm{~h}$ at $110{ }^{\circ} \mathrm{C}$.

In a typical catalytic test, methanol $(5 \mathrm{~mL}$, Fisher Laboratory reagent grade) was added to a flask $(50 \mathrm{~mL})$ containing phenylboronic acid $(0.3 \mathrm{mmol}$, Sigma Aldrich > $97.0 \%$ HPLCgrade), potassium carbonate $(0.4 \mathrm{mmol})$ and catalyst $(100 \mathrm{mg}$ of $1 \mathrm{wt} \% \mathrm{Au} / \mathrm{C})$. Catalytic testing was performed using a Radleys carousel magnetic stirrer at $45^{\circ} \mathrm{C}$ and $800 \mathrm{rpm}$. O-xylene was used as an internal standard. The catalytic activity of gold (III) chloride was tested using a solution of $\mathrm{HAuCl}_{4} .3 \mathrm{H}_{2} \mathrm{O}$ (Alfa Aesar, $99.9 \%$ ). The reaction mixture was analysed using Agilent Technologies 1200 series HPLC equipped with 2 reverse phase columns (Agilent Poroshell 120, SB-C18, 4.6x150 mm, $2.7 \mu \mathrm{m}$ ) connected in series and a DAD detector (G1315D - 1260 DAD VL). Acetonitrile (50 \%, Fischer, HPL gradient grade) and water (50 $\%$, Fischer, HPL gradient grade) was used at the mobile phase $(0.5 \mathrm{~mL} / \mathrm{min})$.

Powder X-ray diffraction (XRD) spectra were acquired between $5^{\circ}$ and $80^{\circ}$ using an X'Pert Pro PAN Analytical powder diffractometer employing a $\mathrm{Cu} \mathrm{K}_{\alpha}$ radiation source operating at $40 \mathrm{keV}$ and $40 \mathrm{~mA}$. Analysis of the spectra obtained was carried out using X'Pert High Score Plus software. In-situ XRD was performed on a Panalytical X'Pert diffractometer with an Anton Paar $900 \mathrm{~K}$ in-situ cell. The XRD spectra were collected at temperatures between $25^{\circ} \mathrm{C}$ and $600{ }^{\circ} \mathrm{C}$ under an $\mathrm{N}_{2}$ flow $(10 \mathrm{~mL} / \mathrm{min})$. The sample was heated at a rate of $10{ }^{\circ} \mathrm{C} / \mathrm{min}$ and was kept for 5 min at a certain temperature before the spectra were collected.

Materials for examination by scanning transmission electron microscopy (STEM) were dry dispersed onto a holey carbon TEM grid. These supported fragments were examined using the HAADF-STEM imaging mode in an aberration corrected JEOL ARM-200CF scanning STEM operating at 200kV. A JEOL 2100 TEM operating at $200 \mathrm{kV}$ was used to study the particle size distribution of the $\mathrm{Au} / \mathrm{C}$ (sol) and spent $\mathrm{Au} / \mathrm{C}(\mathrm{AR})$ catalyst. These samples were dispersed in ethanol and a drop of the solution applied onto a holey carbon TEM grid and allowed to evaporate. ImageJ was used to measure the particle sizes.

XAFS data was collected at the B18 beamline at the Diamond Light Source in Harwell, UK. The measurements were performed using a QEXAFS set-up with a fast-scanning Si (111) 
double crystal monochromator and a 36 element Ge fluorescence detector. Data has been processed using Athena software.

XPS was carried out using a Thermo Scientific K-alpha photoelectron spectrometer with monochromatic $\mathrm{AlK}_{\alpha}$ radiation. The resulting spectra were processed in CasaXPS and calibrated against the $\mathrm{C}(1 \mathrm{~s})$ line at $284.7 \mathrm{eV}$.

SEM imaging on the used catalysts was performed on a Tescan MAIA3 field emission gun scanning electron microscope (FEG-SEM). Samples were dry dispersed onto 300 mesh Cu grid supported holey carbon film and imaged using the backscattered electron detector at 15 $\mathrm{kV}$. Samples were uncoated

\section{Acknowledgements}

We would like to thank MaxNet Energy for financial support. We would also like to thank the Cardiff University TEM facility for the electron microscopy. 
Figure 1 - X-ray diffraction patterns of a) $1 \% \mathrm{Au} / \mathrm{C}$ prepared by sol-immobilisation ( $\mathbf{\square})$ and aqua regia (AR) treatment ( $\square$ b) in-situ X-ray diffraction analysis of the $1 \% \mathrm{Au} / \mathrm{C}(\mathrm{AR})$ catalyst at various elevated temperatures under an inert nitrogen atmosphere.

a)

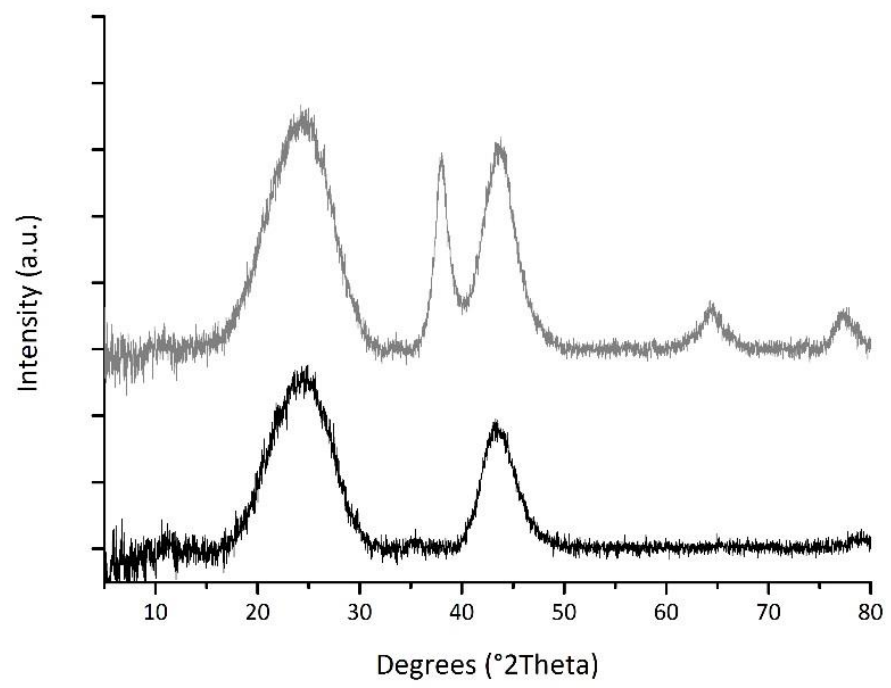

b)

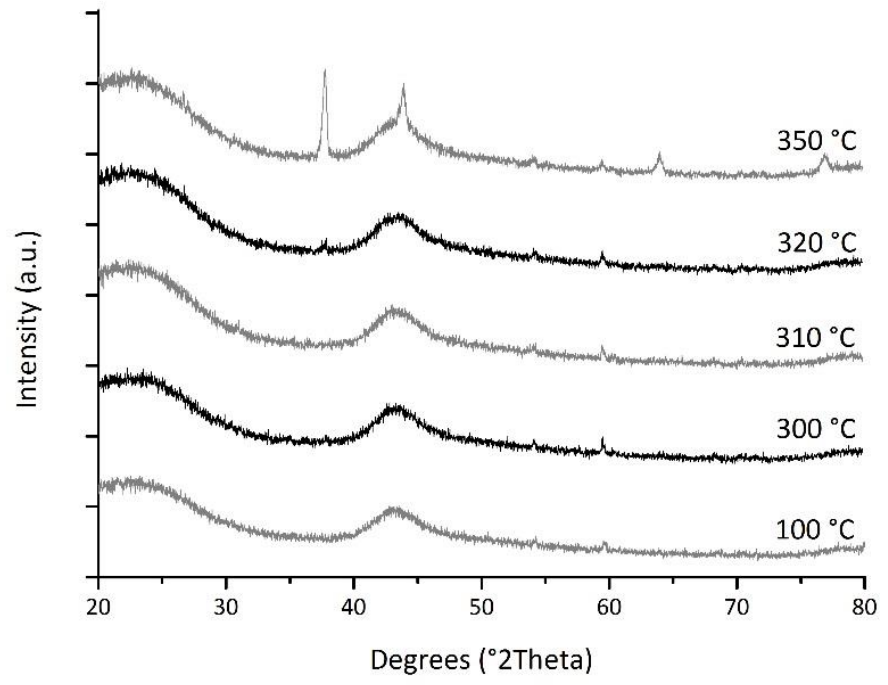


Figure 2 - a) Bright-field TEM micrograph of the $1 \% \mathrm{Au} / \mathrm{C}$ (sol) catalyst, b) its corresponding particle size distribution and c) the Au4f region of its XPS spectrum.

a)

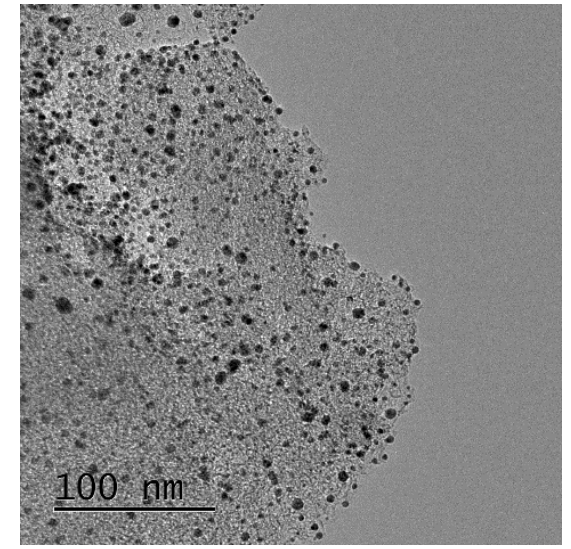

b)

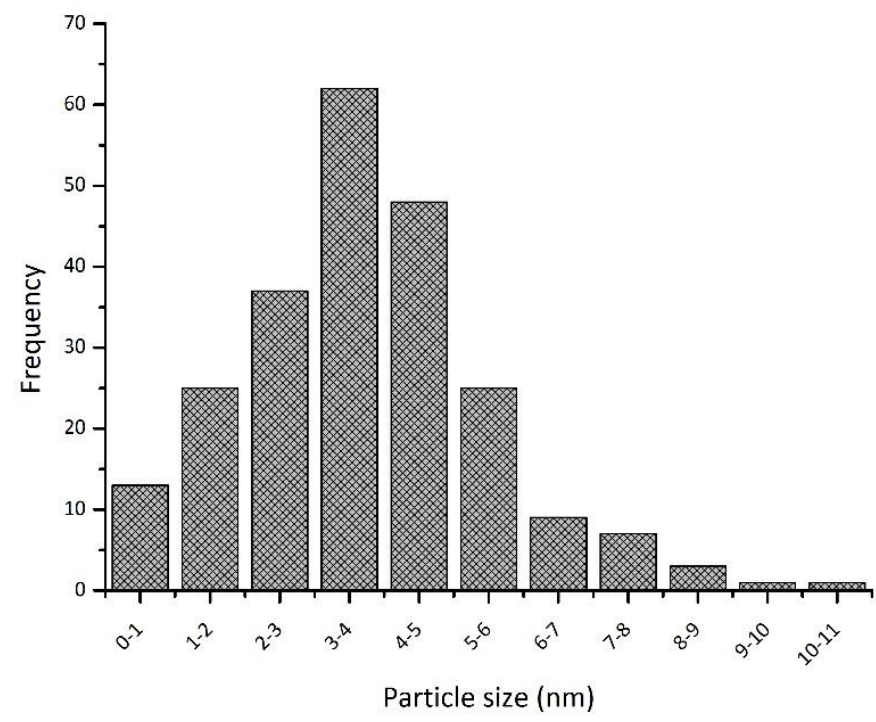

c)

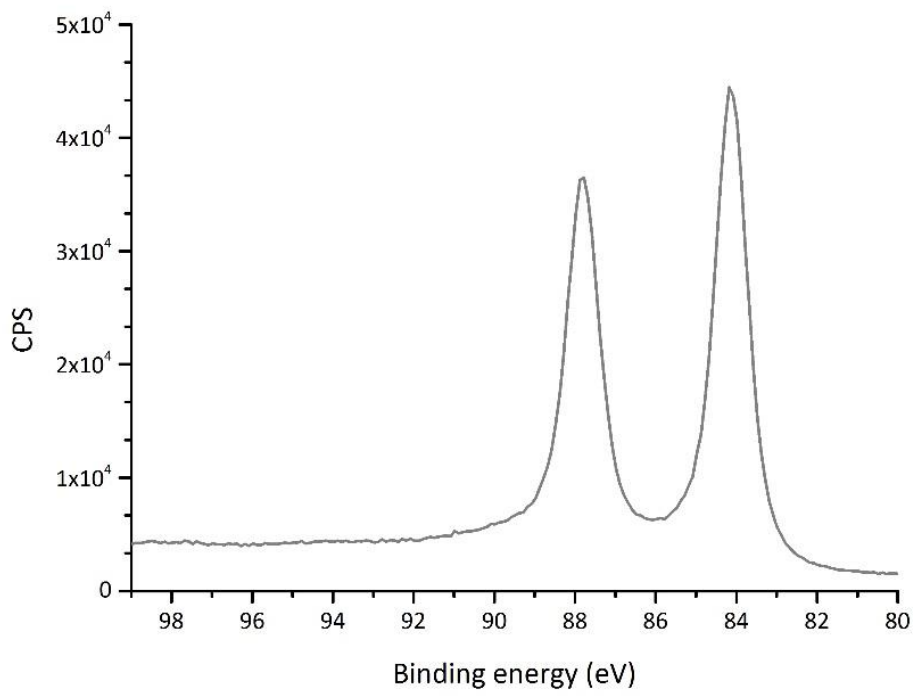


Figure 3 - Representative HAADF-STEM images of atomically dispersed Au species on an aqua regia treated carbon support.

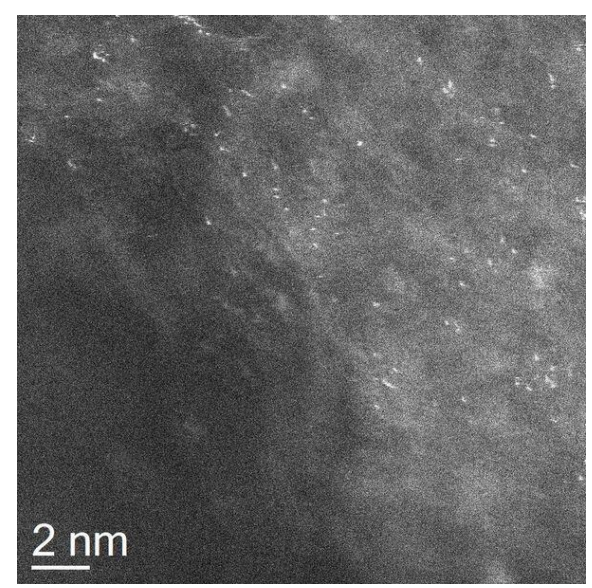


Figure 4 a) Ex-situ Au L $\mathrm{L}_{3}$ edge-normalized XANES spectra of the fresh 1\% Au/C (AR) catalyst $(\mathbf{\square})$ and a gold-foil reference material $(*)$; b) Fourier transform of $\mathrm{k}^{3}$-weighted $\chi$ EXAFS ex-situ data of the fresh $1 \% \mathrm{Au} / \mathrm{C}(\mathrm{AR})$ catalyst (ם) and a gold-foil reference (*). Variation in magnitude of Fourier transform is plotted as function of distance $\mathrm{R}$ from the $\mathrm{Au}$ absorber.

a)

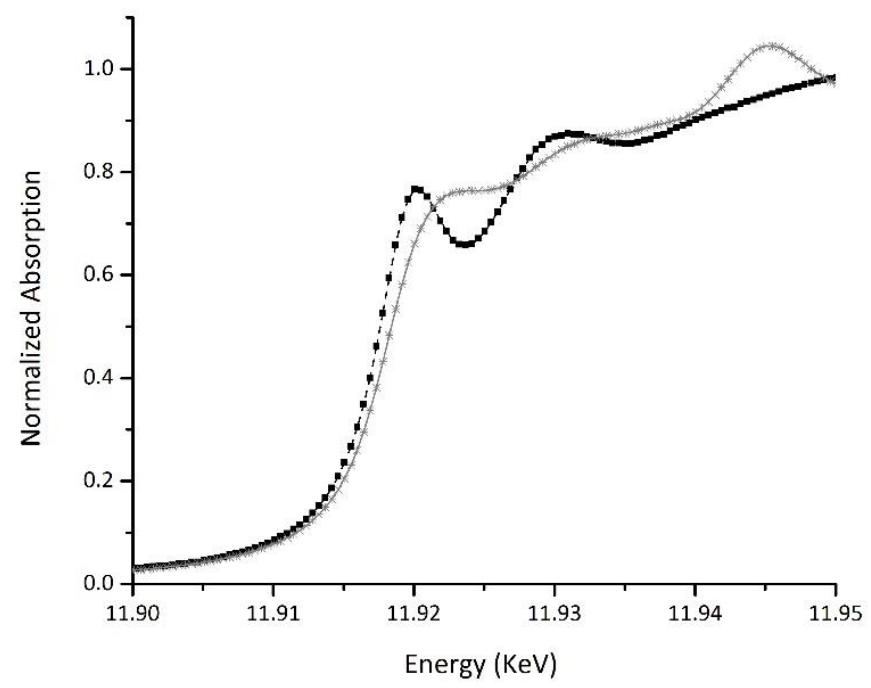

b)

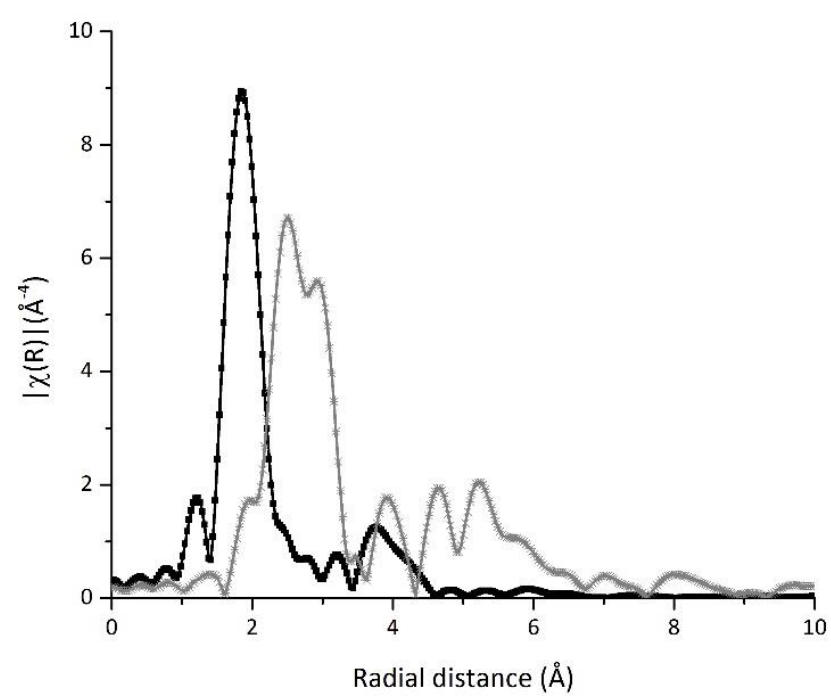


Figure 5 - a) Catalytic activity and b) selectivity data of $1 \% \mathrm{Au} / \mathrm{C}(\mathrm{AR})(\square), 1 \% \mathrm{Au} / \mathrm{C}$ (sol) $(\boldsymbol{\Delta})$ and $\mathrm{HAuCl}_{4}(\bullet)$ for the homocoupling of phenylboronic acid.

a)

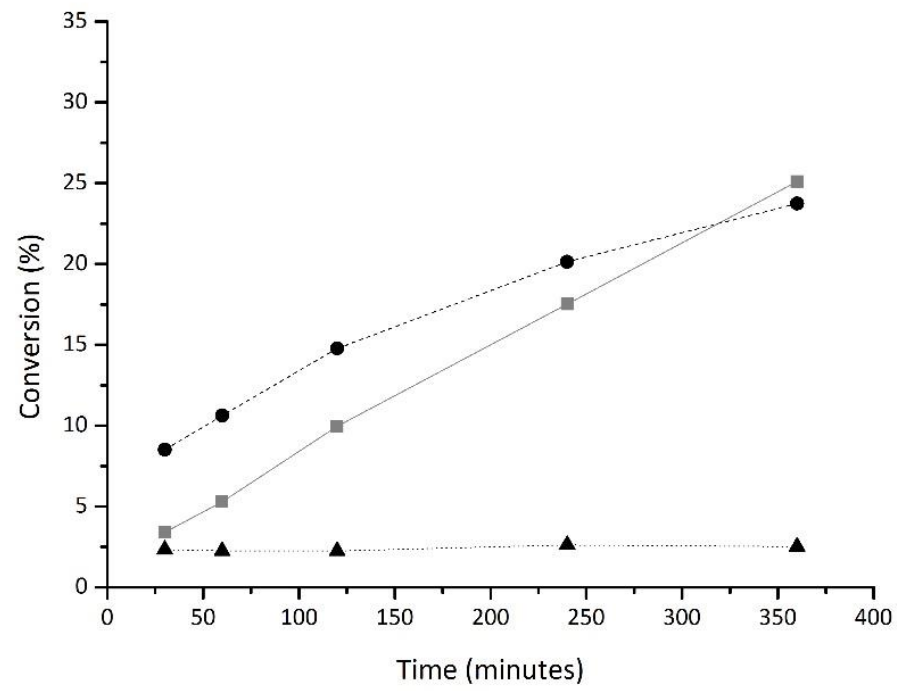

b)

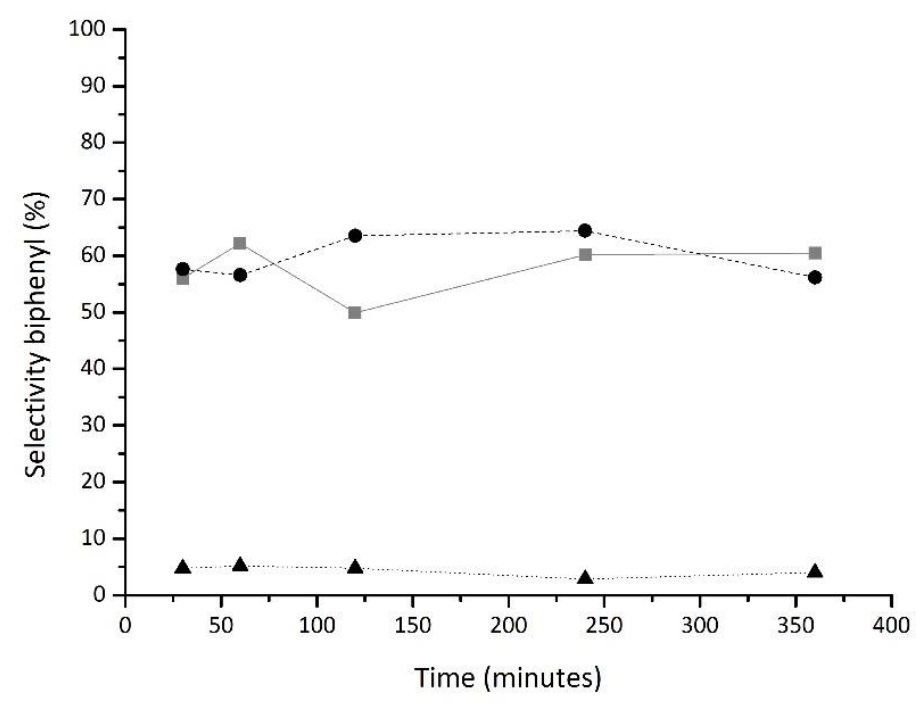

Reaction conditions: Phenylboronic acid $(0.3 \mathrm{mmol}), \mathrm{K}_{2} \mathrm{CO}_{3}(0.4 \mathrm{mmol})$ and catalyst $(100$ $\mathrm{mg}$ of $1 \mathrm{wt} \% \mathrm{Au} / \mathrm{C}$ ) in $5 \mathrm{~mL} \mathrm{MeOH}$. Stirred at $800 \mathrm{rpm}$ at $45^{\circ} \mathrm{C}$. O-xylene was used as an internal standard. 
Figure 6 - a) Ex-situ Au L 3 edge-normalized XANES spectra of a used 1\% Au/C (AR) catalyst ( $\mathbf{\square})$ and a gold-foil reference material (*); b) Fourier transform of $\mathrm{k}^{3}$-weighted $\chi$ EXAFS ex-situ data of the used $1 \% \mathrm{Au} / \mathrm{C}$ (AR) catalyst ( $)$ and a gold-foil reference (*). Variation in magnitude of Fourier transform is plotted as a function of distance $\mathrm{R}$ from the Au absorber.

a)

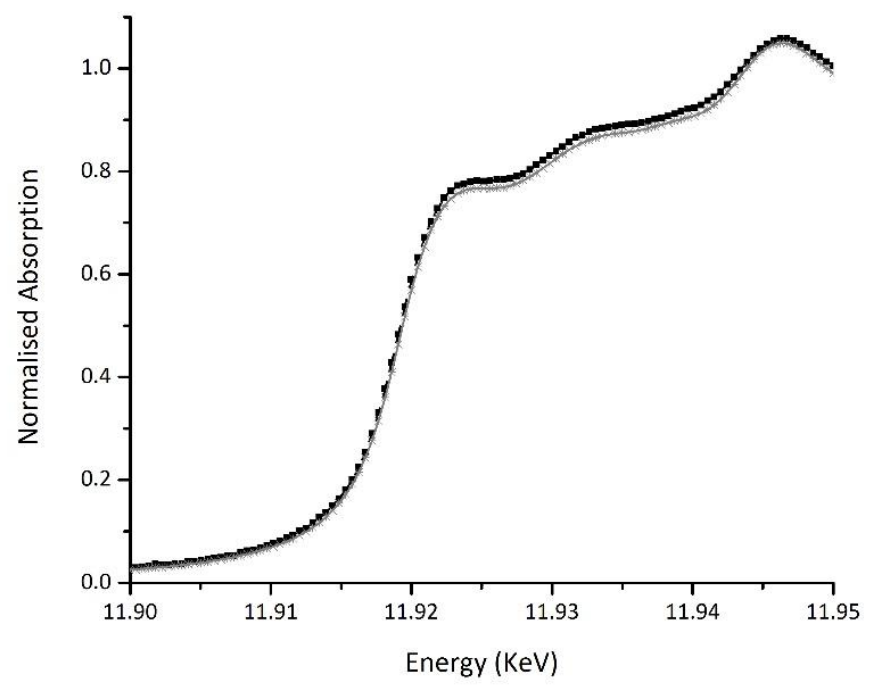

b)

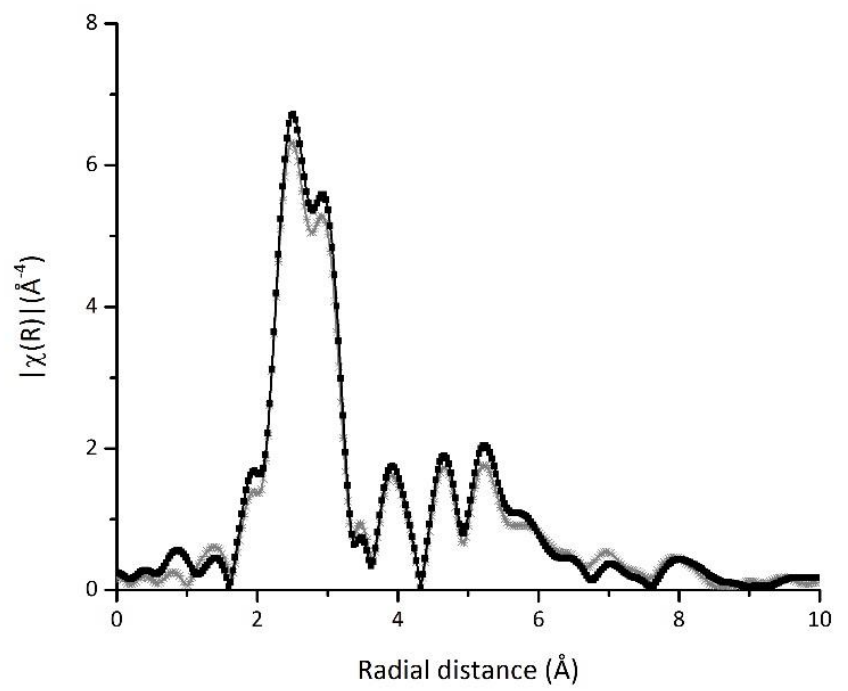


Figure 7 - a) Results from linear combination fitting of the signals of the fresh (left) and used (right) $1 \% \mathrm{Au} / \mathrm{C}(\mathrm{AR})$ catalyst. The different gold phases in this plot are differentiated by the following keys: $\square \mathrm{Au}(0), \square \mathrm{Au}(\mathrm{I})$ and $\square \mathrm{Au}(\mathrm{III}) . \mathrm{b}) \mathrm{BF}-\mathrm{TEM}$ micrograph of the $1 \% \mathrm{Au} / \mathrm{C}$ (AR) catalyst after $6 \mathrm{~h}$ reaction and c) its corresponding particle size distribution.

a)

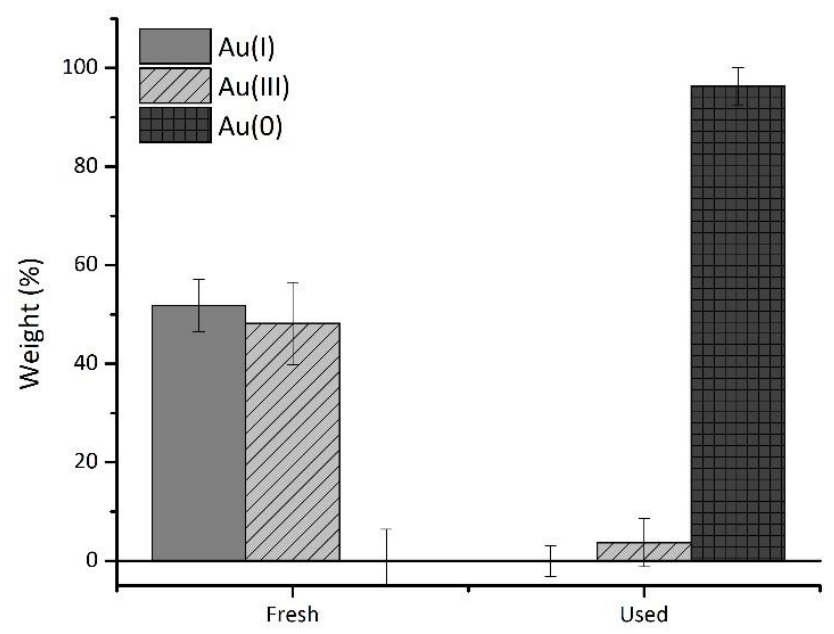

b)

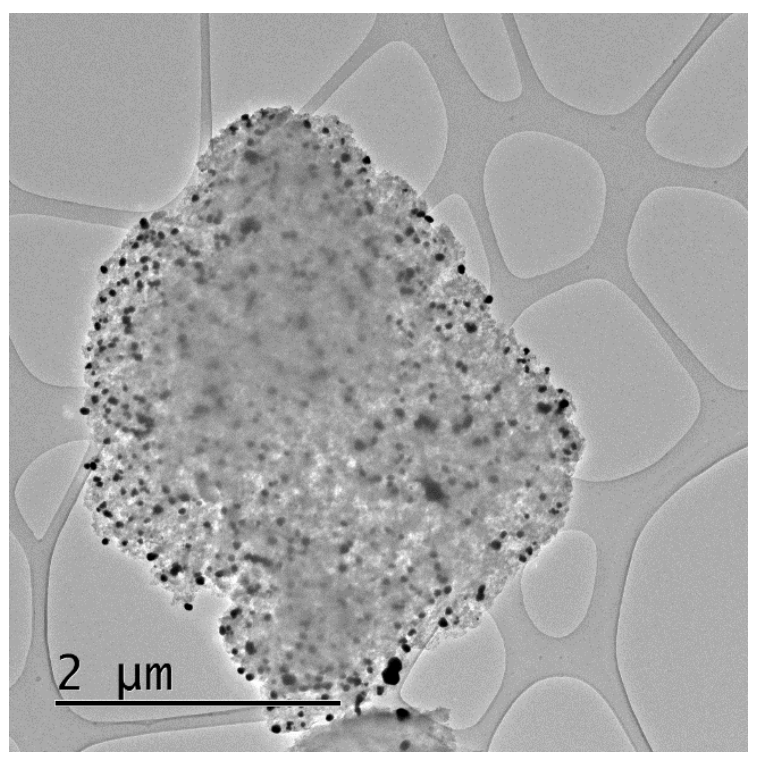


c)

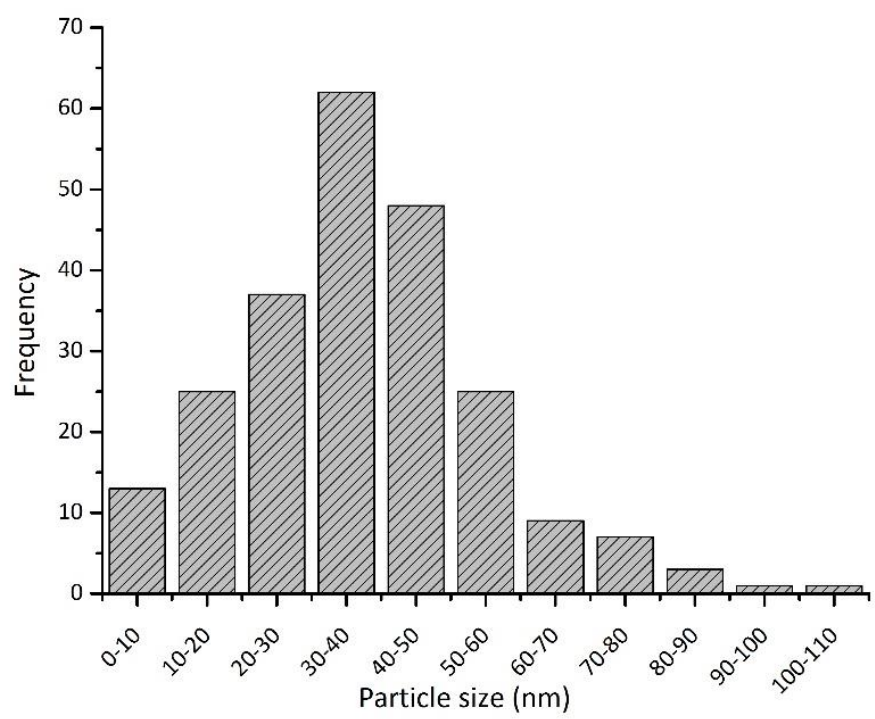


Figure 8 - Conversion versus time-on-line curves for the fresh $1 \% \mathrm{Au} / \mathrm{C}$ (AR) catalyst ( $\mathbf{\square})$ and a used $1 \% \mathrm{Au} / \mathrm{C}(\mathrm{AR})$ catalyst (*).

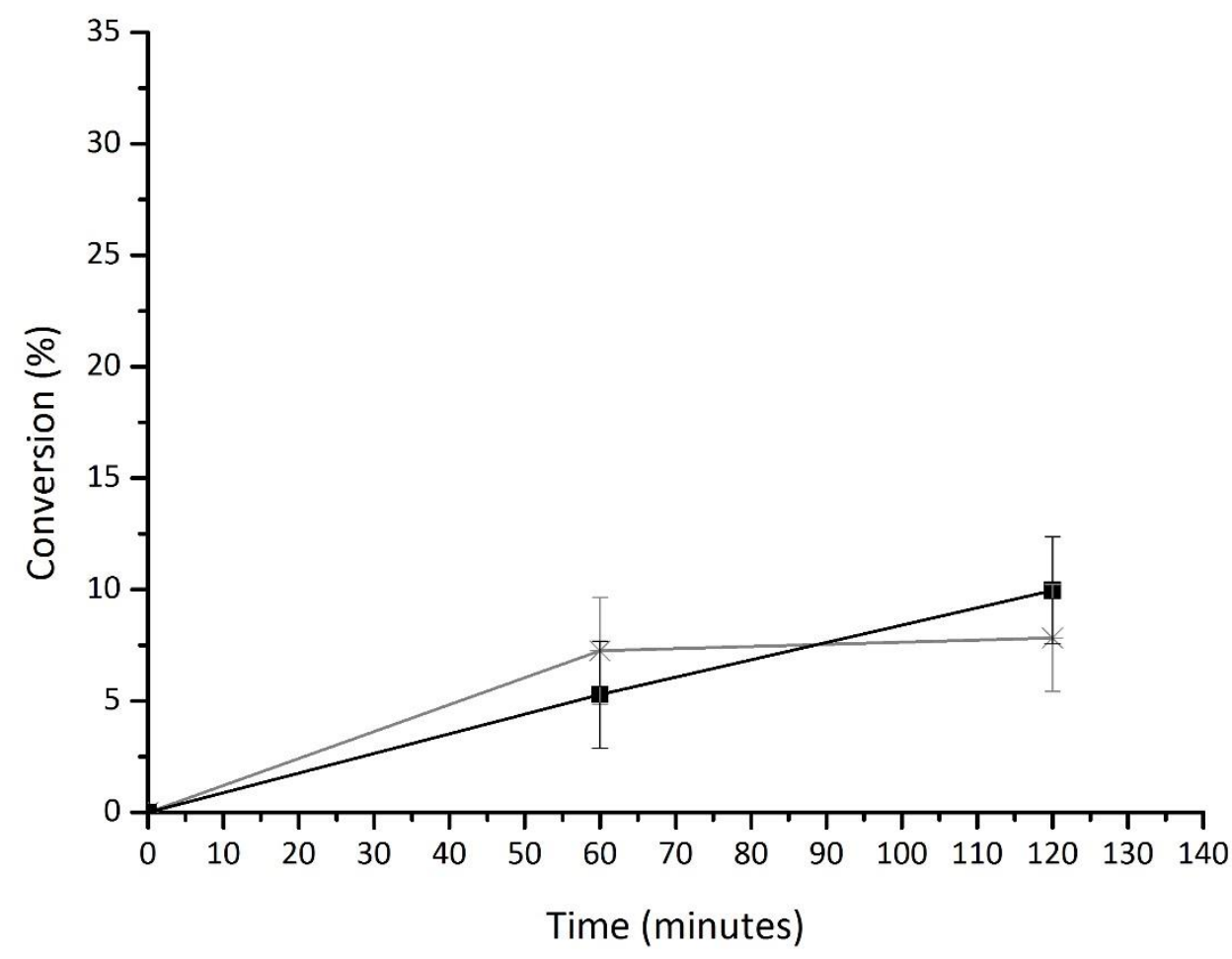


[1] a) T. J. Colacot, Platinum Metals Review 2011, 55, 84-90; b) V. L. Budarin, P. S. Shuttleworth, J. H. Clark, R. Luque, Current Organic Synthesis 2010, 7, 614-627; c) C. Torborg, M. Beller, Advanced Synthesis \& Catalysis 2009, 351, 3027-3043; d) X. F. Wu, P. Anbarasan, H. Neumann, M. Beller, Angew Chem Int Ed Eng/ 2010, 49, 9047-9050.

[2] A. Suzuki, Journal of Organometallic Chemistry 1999, 576, 147-168.

[3] George B. Smith, G. C. Dezeny, D. L. Hughes, A. King, T. R. Verhoeven, Journal of Organometallic Chemistry 1994, 59, 8151-8156.

[4] M. Mora, C. Jimenez-Sanchidrian, J. R. Ruiz, J Colloid Interface Sci 2006, 302, 568-575.

[5] S. Carrettin, J. Guzman, A. Corma, Angew Chem Int Ed Engl 2005, 44, 2242-2245.

[6] a) A. S. Hashmi, A. M. Schuster, F. Rominger, Angew Chem Int Ed Eng/ 2009, 48, 8247-8249; b) A. S. K. Hashmi, R. Döpp, C. Lothschütz, M. Rudolph, D. Riedel, F. Rominger, Advanced Synthesis \& Catalysis 2010, 352, 1307-1314; c) A. S. K. Hashmi, C. Lothschütz, R. Döpp, M. Ackermann, J. De Buck Becker, M. Rudolph, C. Scholz, F. Rominger, Advanced Synthesis \& Catalysis 2012, 354, 133-147.

[7] S. Carrettin, A. Corma, M. Iglesias, F. Sánchez, Applied Catalysis A: General 2005, 291, 247252.

[8] C. Gonzalez-Arellano, A. Corma, M. Iglesias, F. Sanchez, Chem Commun (Camb) 2005, 19901992.

[9] A. S. K. Hashmi, M. C. Blanco, D. Fischer, J. W. Bats, European Journal of Organic Chemistry 2006, 2006, 1387-1389.

[10] T. Matsuda, T. Asai, S. Shiose, K. Kato, Tetrahedron Letters 2011, 52, 4779-4781.

[11] a) S. Witzel, J. Xie, M. Rudolph, A. S. K. Hashmi, Advanced Synthesis \& Catalysis 2017, 359, 1522-1528; b) J. Xie, M. Rudolph, F. Rominger, A. S. K. Hashmi, Angew Chem Int Ed Engl 2017, 56, 7266-7270; c) J. Xie, J. Li, V. Weingand, M. Rudolph, A. S. Hashmi, Chemistry A European Journal 2016, 22, 12646-12650.

[12] N. G. Willis, J. Guzman, Applied Catalysis A: General 2008, 339, 68-75.

[13] a) A. S. K. Hashmi, T. D. Ramamurthi, F. Rominger, Journal of Organometallic Chemistry 2009, 694, 592-597; b) A. S. K. Hashmi, T. D. Ramamurthi, M. H. Todd, B. A. S.-K. Tsang, K. Graf, Australian Journal of Chemistry 2010, 63, 1619-1626.

[14] a) L. Wang, W. Zhang, D. Sheng Su, X. Meng, F. S. Xiao, Chem Commun (Camb) 2012, 48, 5476-5478; b) C.-H. Liu, C.-Y. Lin, J.-L. Chen, N.-C. Lai, C.-M. Yang, J.-M. Chen, K.-T. Lu, Journal of Catalysis 2016, 336, 49-57; c) S. K. Movahed, M. Shariatipour, M. Dabiri, RSC Adv. 2015, 5, 33423-33431.

[15] a) G. Malta, S. A. Kondrat, S. J. Freakley, C. J. Davies, L. Lu, S. Dawson, A. Thetford, E. K. Gibson, D. J. Morgan, W. Jones, P. P. Wells, P. Johnston, C. R. A. Catlow, C. J. Kiely, G. J. Hutchings, Science 2017, 355, 1399-1403; b) XAS has even been used to characterise the oxidation state of gold in homogeneous gold-catalysed oxidative esterfication reactions, see : A. S. Hashmi, C. Lothschutz, M. Ackermann, R. Doepp, S. Anantharaman, B. Marchetti, H. Bertagnolli, F. Rominger, Chemistry A European Journal 2010, 16, 8012-8019.

[16] G. Malta, S. J. Freakley, S. A. Kondrat, G. J. Hutchings, Chem Commun (Camb) 2017, 53, $11733-11746$.

[17] a) Y. Y. Fong, B. R. Visser, J. R. Gascooke, B. C. Cowie, L. Thomsen, G. F. Metha, M. A. Buntine, H. H. Harris, Langmuir 2011, 27, 8099-8104; b) X. Liu, M. Conte, D. Elias, L. Lu, D. J. Morgan, S. J. Freakley, P. Johnston, C. J. Kiely, G. J. Hutchings, Catal. Sci. Technol. 2016, 6, 5144-5153.

[18] Hironori Tsunoyama, Hidehiro Sakurai, Nobuyuki Ichikuni, Yuichi Negishi, T. Tsukuda, Langmuir 2004, 20, 11293-11296.

[19] C. Gonzalezarellano, A. Corma, M. Iglesias, F. Sanchez, Journal of Catalysis 2006, 238, 497501.

[20] P. Johnston, N. Carthey, G. J. Hutchings, J Am Chem Soc 2015, 137, 14548-14557. 
